\section{Cultural characteristics and antibiotic susceptibility pattern of Helicobacter Pylori isolated from dyspepsia patients}

\author{
Bolanle A. Adeniyi, ${ }^{1}$ Temitope O. Lawal, \\ Jesse A. Otegbayo, ${ }^{2}$ \\ Olayiwola A. Oluwasola, ${ }^{3}$ \\ Georgina N. Odaibo, ${ }^{4}$ Samuel O. Ola, ${ }^{2}$ \\ Clement A. Okolo, ${ }^{3}$ Adegboyega Akere, ${ }^{2}$ \\ Aderemi O. Kehinde ${ }^{5}$ \\ Departments of ${ }^{1} \mathrm{Ph}$ armaceutical \\ Microbiology, ${ }^{2}$ Medicine, ${ }^{3}$ Pathology, \\ ${ }^{4}$ Virology and 5 Medical Microbiology, \\ University of Ibadan, Nigeria
}

\section{Abstract}

Helicobacter pylori consist in a helical shaped Gram-negative bacterium, approximately 3 micrometers long with a diameter of approximately 0.5 micrometers. It has $4-6$ flagella. It is microaerophilic and tests positive for oxidase, catalase and urease. With its flagella, the bacterium moves through the stomach lumen and drills into the mucus gel layer of the stomach. In humans, $H$. pylori have been associated with peptic ulcers, chronic gastritis, duodenitis and stomach cancer. It is widely believed that in the absence of treatment, $H$. pylori infection, once established in its gastric niche, persists for life. The aim of this research is to study the cultural characteristics and antibiotic susceptibility pattern of $H$. pylori strains isolated from southwest Nigeria. The cultural characteristics and antibiotic susceptibility pattern of Helicobacter pylori strains isolated from gastric mucosal antral biopsy specimens collected from 43 of 52 dyspepsia patients in the University College Hospital Ibadan, Oyo State, Nigeria, were determined using standard microbiological methods for Helicobacter pylori isolation. The 43 isolates were subjected to 23 different antibiotics and each of the antibiotics demonstrated a variable degree of activity against the isolates. Among the antibiotics to which the organism was most susceptible are: ofloxacin (30 $\mu \mathrm{g})$ 100\% activity, ciprofloxacin $(5 \mu \mathrm{g})$ $97.67 \%$ activity, gentamicin $(120 \mu \mathrm{g}) 95.35$ activity, amikacin $(30 \mu \mathrm{g})$, kanamycin $(30 \mu \mathrm{g})$ and chloramphenicol $(30 \mu \mathrm{g})$ each $90.70 \%$ activity, clarithromycin (15 $\mu \mathrm{g})$ 93.02, while the less active antibiotics are: augmentin (30 $\mu \mathrm{g}) 23.26 \%$ active, amoxycillin $(25 \mu \mathrm{g})$ and metronidazole $(50 \mu \mathrm{g})$ each $27.91 \%$ active and clindamycin (2 mg) $30.23 \%$ active. From the result of the antibiotic susceptibility pattern of the strains of the organism, $95.35 \%$ of the total isolates are multi drug resistant. Resistance was developed to, among others, augmentin $(30 \mu \mathrm{g})$, amoxycillin $(25 \mu \mathrm{g})$, metronidazole $(50 \mu \mathrm{g})$ and clindamycin $(2 \mathrm{mg})$.

\section{Introduction}

Helicobacter pylori consist of a helical shaped Gram-negative bacterium, approximately 3 micrometers long with a diameter of approximately 0.5 micrometers. It has 4-6 flagella. It is microaerophilic and tests positive for oxidase, catalase and urease. ${ }^{1}$ Helicobacter pylori produce adhesins that help its adhesion to epithelial cells. They produce a large amount of urease enzymes that are localized inside and outside of the bacterium. Urease metabolizes urea (which is normally secreted into the stomach) to carbon dioxide and ammonia (which neutralizes gastric acid). The survival of $H$. pylori in the acidic stomach is dependent on urease, and it would eventually die without it. The ammonia that is produced is toxic to the epithelial cells, and together with the other products of $H$. pylori (including protease, catalase and certain phospholiphase) causes damage to those cells.

Several strains of $H$. pylori are known, and the genomes of two have been completely sequenced (see http:genolist.pasteur. fr/pyloriGene). ${ }^{2}$ Study of the $H$. pylori genomes is aimed at understanding pathogenesis, the ability of this organism to cause disease. Infection of $H$. pylori may be symptomatic or asymptomatic. It is estimated that up to $70 \%$ of infection is asymptomatic and that about twothirds of the world population are infected by the bacterium, making it the most widespread infection in the world. Actual prevalence of the infection varies from country to country. In humans, $H$. pylori have been associated with peptic ulcers, chronic gastritis, duodenitis and stomach cancer. It is widely believed that in the absence of treatment, $H$. pylori infection, once established in its gastric niche, persists for life. ${ }^{3,4}$ Helicobacter pylori infection is transmitted orally by means of fecal matter through the ingestion of waste-tainted food or water.

In peptic ulcer patients where infection is detected, the normal treatment procedure is eradicating $H$. pylori to allow the ulcer to heal. The standard first-line therapy is a one week triple therapy amoxicillin, clarithromycin and a proton pump such as omeprazole, pantoprazole or rabeprazole, and the use of metronidazole instead of amoxycillin in those allergic to penicillin. ${ }^{5,6}$ Resistance of $H$. pylori to metronidazole and macrolides has emerged worldwide and now constitutes a major problem in therapy. ${ }^{7-9}$ This justifies the increasing use of culture in testing for $H$. pylori infection
Correspondence: Bolanle A. Adeniyi, Department of Pharmaceutical Microbiology, University of Ibadan, Nigeria. Tel. +23.4802 .3451480 .

E-mail: baadeniyi@yahoo.co.uk

Key words: Helicobacter pylori, cultural characteristics, antibiotics susceptibility pattern, multi

Contributions: BAA, project planning, susceptibility testing, results evaluation, manuscript writing; TOL, susceptibility testing, results evaluation, manuscript writing; JAO, project planning, patients examinations, endoscopies; S00, AA, collection of biopsy from patients; A00, AOK, project planning; GNO, CAO, results evaluation.

Funding: this work was funded by a MacArthur Multidisciplinary Research Grant to the authors.

Conflict of interests: the authors report no conflict of interests.

Received for publication: 24 January 2012.

Revision received: 13 May 2012.

Accepted for publication: 10 July 2012.

This work is licensed under a Creative Commons Attribution NonCommercial 3.0 License (CC BYNC 3.0).

(C) Copyright B.A. Adeniyi et al., 2012 Licensee PAGEPress, Italy

Gastroenterology Insights 2012; 4:e21 doi:10.4081/gi.2012.e21

because it is the only diagnostic method that allows the susceptibility of this organism to antimicrobial agents to be assessed. The objective of this research is to study the cultural characteristics and antibiotic susceptibility pattern of $H$. pylori strains isolated from southwest Nigeria.

\section{Materials and Methods}

\section{Biopsy specimens and culture}

Gastric mucosal antral biopsy specimens were collected from each of 52 consecutive dyspeptic patients (35 females aged 10-80 years; 17 males aged 10-90 years) undergoing endoscopy. Gastric biopsy specimens were placed in sterile tubes containing $0.5 \mathrm{~mL}$ of transport medium consisting of sterile physiological normal saline, and were kept at $4^{\circ} \mathrm{C}$. The interval between the removal of the specimens and the inoculation onto culture media did not exceed $3 \mathrm{~h}$. The biopsy specimens were removed from the transport tubes and placed in fresh sterile tubes containing $0.5 \mathrm{~mL}$ saline. The biopsy specimens were then finely mixed in a tissue grinder to dislodge the organisms. One hundred microliters $(100 \mu \mathrm{L})$ from each 
solution were placed for isolation on agar plates. The plates were incubated in $100 \%$ humidity at $37^{\circ} \mathrm{C}$ for up to seven days in a microaerophilic gas mixture composed of $10 \%$ $\mathrm{CO}_{2}, 5 \% \mathrm{O}_{2}$, and $85 \% \mathrm{~N}_{2}$ (Campy-Pak; Unipak S.p.A, Milan, Italy). The agar plates were checked for growth from day 3 through day 7 . An isolate was identified as $H$. pylori on the bases of positive catalase, oxidase, and urease reaction, typical colony morphology (small round colonies), and the presence of characteristic curved gram-negative bacilli on Gramstrained smears. The identified colonies were then sub-cultured in alkaline peptone water.

\section{Susceptibility testing}

The isolates were grown in alkaline peptone water to their exponential growth phase and standardized to $0.5 \mathrm{McF}$ arland standards $\left(10^{8}\right.$ $\mathrm{CFU} / \mathrm{mL}) ; 200 \mu \mathrm{L}$ of the standardized cell suspensions were evenly spread over the solidified Mueller-Hinton agar plates and the plates were allowed to dry. Concentrations ranging between $5-300 \mu \mathrm{g} / \mathrm{mL}$ (except clindamycin which was in milligrams, $\mathrm{mg}$ ) of 23 antibiotics in discs $(4 \mathrm{~mm})$ were placed on the agar sur- face using a sterile forceps. The following antibiotics were tested: augmentin, amoxycillin, erythromycin, tetracycline, cloxacillin, gentamicin, cotrimoxazole, chloramphenicol, nitrofurantoin, nalidixic acid, ofloxacin, clarithromycin, metronidazole, cefsulodin, cephradine, vancomycin, tobramycin, kanamycin, clindamycin, amikacin, ciprofloxacin, amoxicillin/clavulanic acid and ampicillin. The plates were incubated under microaerophilic condition as above for $48-72 \mathrm{~h}$ after which the zones of inhibition were measured for active drugs.

\section{Results}

There were no organisms isolated from samples 1 and 2 hence no further tests were carried out. The Gram negative organisms isolated from samples 14, 17, 20, 31, 41 and 45 gave positive result for catalase and urease tests whereas they tested negative for oxidase test. Isolates from the other $(n=44)$ samples were Gram-negative rods, tested positive for catalase, urease and oxidase tests. An isolate was identified as $H$. pylori on the basis of positive catalase, oxidase, and urease reactions, typical colony morphology (small round colonies), the presence of characteristic curved Gram-negative bacilli on Gram-stained smears and its growth in a microaerophilic environment. The diameter zone of inhibition was interpreted as resistance when the zone size is $6 \mathrm{~mm}$ or under, intermediate when the zone size is $7-10 \mathrm{~mm}$ and sensitive when the zone size is $11 \mathrm{~mm}$ or over.

The percentage susceptibility of Helicobacter pylori strains to various antibiotics are shown in Table 1.

\section{Discussion}

Culture of $H$. pylori has two major advantages. Firstly, it allows antimicrobial susceptibility testing and secondly, isolates obtained by culture can be characterized in detail. Although the sensitivity of culture in experienced and well-equipped laboratories is greater than $95 \%$, other methods for the diag-

Table 1. Percentage susceptibility of Helicobacter pylori strains to various antibiotics.

\begin{tabular}{|c|c|c|c|c|c|c|c|}
\hline $\mathbf{S} / \mathbf{N}$ & Antibiotics & $\begin{array}{l}\text { N. susceptible } \\
\text { isolates }\end{array}$ & $\begin{array}{l}\text { N. partially } \\
\text { susceptible } \\
\text { isolates }\end{array}$ & $\begin{array}{l}\text { N. resistant } \\
\text { isolates }\end{array}$ & $\begin{array}{l}\text { Percentage } \\
\text { susceptible } \\
\text { isolates }\end{array}$ & $\begin{array}{c}\text { Percentage } \\
\text { partially susceptible } \\
\text { isolates }\end{array}$ & $\begin{array}{l}\text { Percentage } \\
\text { resistant } \\
\text { isolates }\end{array}$ \\
\hline 1. & Augmentin $(30 \mu g)$ & 4 & 6 & 33 & 9.4 & 13.9 & 76.8 \\
\hline 2. & Amoxicillin $(25 \mu \mathrm{g})$ & 2 & 10 & 31 & 4.7 & 23.2 & 72.1 \\
\hline 3. & Erythromycin $(5 \mu \mathrm{g})$ & 11 & 13 & 19 & 25.6 & 30.2 & 44.2 \\
\hline 4. & Tetracycline $(10 \mu g)$ & 4 & 16 & 23 & 9.4 & 37.2 & 53.5 \\
\hline 5. & Tetracycline $(30 \mu g)$ & 11 & 16 & 16 & 25.6 & 37.2 & 37.2 \\
\hline 6. & Cloxacillin $(5 \mu \mathrm{g})$ & 11 & 11 & 21 & 25.6 & 25.6 & 48.8 \\
\hline 7. & Gentamicin $(10 \mu g)$ & 27 & 5 & 11 & 62.8 & 11.6 & 25.6 \\
\hline 8. & Gentamicin $(12 \mu \mathrm{g})$ & 30 & 11 & 2 & 69.8 & 25.6 & 4.6 \\
\hline 9. & Cotrimoxazole $(25 \mu \mathrm{g})$ & 12 & 4 & 27 & 27.9 & 9.4 & 62.7 \\
\hline 10. & 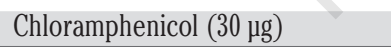 & 33 & 6 & 4 & 76.7 & 13.9 & 9.4 \\
\hline 11. & Nitrofuratoin $(300 \mu \mathrm{g})$ & 21 & 17 & 5 & 48.8 & 39.6 & 11.6 \\
\hline 12. & Nalidixic acid $(30 \mu \mathrm{g})$ & 32 & 6 & 5 & 74.5 & 13.9 & 11.6 \\
\hline 13. & Ofloxacin $(30 \mu \mathrm{g})$ & 42 & 1 & 0 & 97.6 & 2.4 & 0.00 \\
\hline 14. & Clarithromycin $(15 \mu \mathrm{g})$ & 27 & 13 & 3 & 62.8 & 30.3 & 6.9 \\
\hline 15. & Metronidazole $(50 \mu g)$ & 5 & 7 & 31 & 11.6 & 16.3 & 72.1 \\
\hline 16. & Cefsulodin $(30 \mu \mathrm{g})$ & 19 & 9 & 15 & 44.2 & 20.9 & 34.9 \\
\hline 17. & Cephradin $(30 \mu \mathrm{g})$ & 13 & 12 & 18 & 30.2 & 27.9 & 41.9 \\
\hline 18. & Vancomycin $(5 \mu g)$ & 12 & 7 & 24 & 27.9 & 16.3 & 55.8 \\
\hline 19. & Tobramycin $(10 \mu g)$ & 28 & 8 & 7 & 65.1 & 18.6 & 16.3 \\
\hline 20. & Kanamycin $(30 \mu g)$ & 28 & 11 & 4 & 65.1 & 25.6 & 9.3 \\
\hline 21. & Clindamycin (2 mg) & 7 & 6 & 30 & 16.3 & 13.9 & 69.8 \\
\hline 22. & Amikacin $(30 \mu \mathrm{g})$ & 28 & 10 & 5 & 65.1 & 23.3 & 11.6 \\
\hline 23. & Ciprofloxacin $(5 \mu g)$ & 40 & 2 & 1 & 93.0 & 4.7 & 2.3 \\
\hline 24. & Amoxicillin/clavulanic acid $(30 \mu \mathrm{g})$ & 11 & 6 & 26 & 25.6 & 13.9 & 60.5 \\
\hline 25. & Ampicillin $(30 \mu g)$ & 11 & 17 & 15 & 25.6 & 39.5 & 34.9 \\
\hline
\end{tabular}


nosis of H. pylori infection are simpler, prone to less variability, and faster. Culture of $H$. pylori is very important in the search for efficient antimicrobial combinations that eradicate this bacterium from the stomach. In this study, biochemical tests (positive catalase, oxidase, and urease reactions), typical colony morphology (small round colonies), the presence of characteristic curved Gram-negative bacilli on Gram-stained smears, and growth in a microaerophilic environment, were important parameters in the identification of Helicobacter pylori from gastric mucosal antral biopsy. $H$. pylori isolates identified based on the above parameters were studied for their antimicrobial susceptibility. Susceptibility testing of $H$. pylori gave varied susceptibility patterns as seen in Table 1. This reveals the therapeutic challenge in the treatment of $H$. pylori infection in most developing countries.

Antibiotic resistance is a major cause of treatment failure. ${ }^{10}$ The prevalence of antimicrobial resistance in $H$. pylori shows regional variation both within and between countries. Alternative antibiotics based on local resistance rates may accelerate eradication rates. Clarithromycin resistance has a greater effect on treatment efficacy than nitroimidazole resistance. ${ }^{11}$ The widespread and sometimes indiscriminate use of antibiotics in developing counties has resulted in a higher prevalence of resistance than in developed counties. ${ }^{3}$ Clarithromycin resistance rates in the USA have a prevalence of $10-12.5 \% .^{12,13}$ In Canada, clarithromycin resistance is estimated to be less than $4 \% .{ }^{14}$ In Europe, there is a marked difference between clarithromycin resistance rate in northern, eastern and southern Europe with resistance rates of $4.2 \%, 9.3 \%$ and $18 \%$, respectively. ${ }^{15}$ In this study, $6.9 \%$ resistance to clarithromycin (Table 1) was recorded and this falls within the rate reported in Europe. The prevalence of secondary clarithromycin resistance is extremely high at up to $60 \%{ }^{14}$ Resistance to metronidazole is much more common than resistance to macrolides. In developed countries, approximately $35 \%$ of $H$. pylori strains are resistant to nitroimidazoles whereas in developing countries the resistance rates are higher. ${ }^{16}$ As seen in the results (Table 1), 72.1\% resistance to metronidazole was recorded thus agreeing with the reports that metronidazole resistance is higher in developing countries. ${ }^{15}$ Although metronidazole resistance in vitro does not always predict treatment failure, there is poor correlation between different methods of metronidazole resistance detection and this may explain differing resistance rates between regions. Metronidazole is more commonly used in developing countries for the treatment of para- sitic infections. In developed countries, it is mainly used for dental and gynecological infections, and in some studies, resistance is commonly found in females. ${ }^{14}$ The prevalence of amoxicillin resistance is low $(<1 \%)$. In areas where penicillin is available without prescription, it may be higher. This explains the high rate of resistance to amoxicillin (72.1\%) as found in this study. Tetracycline resistance is estimated to be less than $1 \%$ but in our study, $37.2 \%$ resistance to tetracycline was recorded. This is due to the indiscriminate use of tetracycline in most developing countries. Fluoroquinolones have been being increasingly prescribed in recent years and this has led to increasing resistance rates. In this present study, the result showed very high primary resistance to antibiotics. Helicobacter pylori resistance rate was $6.9 \%$ for clarithromycin $(15 \mu \mathrm{g}), 72.1 \%$ for metronidazole $(50 \mu \mathrm{g}), 0 \%$ for ofloxicin $(30 \mu \mathrm{g}), 4.7 \%$ for gentamycin $(120$ $\mu \mathrm{g}), 37.2 \%$ for tetracycline $(30 \mu \mathrm{g})$ and $34.9 \%$ for ampicillin $(30 \mu \mathrm{g})$ (Table 1). Studies have shown that eradication rates of $H$. pylori were not affected by the duration of treatment or the indication for treatment. ${ }^{17}$

\section{Conclusions}

In this era of increasing clarithromycin use, the effectiveness and the efficacy of standard triple-therapy regimen for $H$. pylori eradication needs to be reassessed.

\section{References}

1. Olson JW, Maier RJ. Molecular hydrogen as an energy source for Helicobacter pylori. Science 2002;298:1788-90.

2. Tomb JF, White 0, Kerlavage AR, et al. The complete genome sequence of the gastric pathogen Helicobacter pylori. Nature 1998;288:539-47.

3. Goodman K, Cockburn M. The role of epidemiology in understanding the health effects of Helicobacter pylori infection after eradication. Med J Australia 2001; 151:431-5.

4. Goodman K, 0' Rourke K, Day R, et al. Dynamics of Helicobacter pylori infection in a US-Mexico cohort during the first two years of life. Int J Epidemiol 2005;34:134855.

5. European Helicobacter pylori Study group 2006. Current concepts in the management of $\mathrm{H}$. pylori infection. The Maastricht 2-2000 consensus. Available from: http:/www. noster.com/fReport.htm. Accessed on September 30, 2006.

6. Mirbagheri SA, Mehrdad H, Mehdi A, Armin R. Triple, standard quadruple and ampicillin - sublactam - based quadruple therapies for H. pylori eradication: a comparative three-armed randomized clinical trial. World J Gastroenterol 2006;12:488891.

7. Cayla R, Lamonliatte H, Megraud F, Quinton A. Primary resistance of Helicobacter pylori strains to metronidazole and clarithromycin in France in 1993. Gastroenterology 1994;106:A61.

8. Olson C, Edmonds A. H. pylori to clarithromycin compared to metronidazole in patients with duodenal ulcers associated with H. pylori infection. Gut 1995;37 Suppl2:A814.

9. Tytgat GNJ, Noah LA. H.pylori eradication. In: Hunt RH, Tytgat GHJ, editors. Helicobacter pylori: basic mechanisms to clinical cure. Dordrecht: Kluwer Academic Publishers; 1994. pp. 550-559.

10. Megraud F. H. pylori antibiotic resistance: prevalence, importance, and advances in testing. Gut 2007;56:1374-81.

11. Fischbach L, Evans EL Meta-analysis: the effect of antibiotic resistance status on the efficacy of triple and quadruple first-line therapies for Helicobacter pylori. Ailment Pharmacol Ther 2007,26:343-57.

12. Duck WM, Sobel J, Pruckler JM,et al. Antimicrobial resistance incidence and risk factors among Helicobacter pylori infected person, United States. Emerg Infect Dis 2004;10:1088-94.

13. Meyer JM, Sillman NP, Wang W, et al. Risk facts for Helicobacter pylori antimicrobial resistance in the United States: the surveillance of $H$. pylori antimicrobial resistance partnership (SHARP) study, 19931999, Ann Intern Med 2002;136:13-24.

14. Mégraud F, Lehours P. Helicobacter pylori detection and antimicrobial susceptibility testing. Clin Microbiol Rev 2007;20:280322.

15. Glupczynski Y, Megraud F, Lopez-Brea M, et al. European multicenter survey of in vitro antimicrobial resistance Helicobacter pylori. Eur J Clin Microbiol Infect Dis 2000; 11:820-3.

16. Gerrits MM, van Vliet AH, Kuipers E, Kusters JG. Helicobacter pylori and antimicrobial resistance: molecular mechanisms and clinical implications. Lancet Infect Dis 2006;6:699-709.

17. Kadayifci A, Buyukhatipoglu H, Cemil Savas M, Simsek I. Eradication of Helicobacter pylori with triple therapy: an epidemiologic analysis of trends in Turkey over 10 years. Clin Ther 2006;28:1960-6. 